\title{
Appropriateness of treatment recommendations for PPI in hospital discharge letters
}

\author{
Dirk Ahrens • Jean-François Chenot • Gesa Behrens • \\ Thomas Grimmsmann • Michael M. Kochen
}

Received: 15 April 2010 / Accepted: 10 July 2010 /Published online: 6 August 2010

(C) The Author(s) 2010. This article is published with open access at Springerlink.com

\begin{abstract}
Purpose The reasons for the dramatic increase in proton pump inhibitors (PPI) prescriptions remain unclear and cannot be explained solely by increased morbidity, new indications or a decrease in alternative medication. Inappropriate use and discharge recommendations in hospitals are considered to be possible explanations. As the quality of PPI recommendations in hospital discharge letters in Germany has not been investigated to date, we have studied the appropriateness of these referrals.

Methods Hospital discharge letters with recommendations for PPI medication from 35 primary care practices in the county of Mecklenburg-Western Pomerania (MV; Northeast Germany) were collected and analysed, and the appropriateness of the PPI indication was rated.

Results No information justifying the recommendation for continuous PPI medication could be identified in $54.5 \%$ of the discharge letters; in $12.7 \%$, the indication was uncertain, and in $32.7 \%$, we found an evidence-based indication for PPI medication. The most common indication for adequate PPI use was nonsteroidal anti-inflammatory drug-prophylaxis in high-risk patients.

Conclusions Inadequate recommendations for PPIs in discharge letters are frequent. This may lead to a continu-
\end{abstract}

Dirk Ahrens and Jean-François Chenot contributed equally to this work

D. Ahrens $\cdot$ J.-F. Chenot $(\square) \cdot$ G. Behrens $\cdot$ M. M. Kochen Department of General Practice, University of Göttingen, Humboldtallee 38,

37073 Göttingen, Germany

e-mail: jchenot@gwdg.de

T. Grimmsmann

Medical Review Board of the Statutory Health Insurance Funds

Mecklenburg-Vorpommern,

Schwerin, Germany ation of this therapy in primary care, thereby unnecessarily increasing polypharmacy and the risk of adverse events as well as burdening the public health budget. Hospitals should therefore critically review recommendations for PPI medication and the dosage thereof in their discharge letters and clearly document the reason for PPI use and the need for continuous prescription in primary care.

Keywords Proton pump inhibitors · Germany

\section{Introduction}

Proton pump inhibitors (PPIs) are the most potent medications currently available to reduce gastric acid secretion. Their use is widespread and on the increase, with annual sales worldwide that have surpassed US $\$ 25$ billion. The prescribing of PPIs in Germany rose from 44 million defined daily doses (DDD) in 1993 to 1,674 million DDD in $2008(+3,805 \%)$, with an associated cost of 540 million Euros per year. The reasons for this are unclear and cannot be explained solely by increased morbidity, new indications [1] or a decrease in alternative medication.

PPIs are indicated for the treatment of gastrooesophageal reflux disease (GERD) [2], peptic ulcer [3] and, in combination with two suitable antibiotics, for the eradication of Helicobacter pylori infection. After eradication, continuation of PPI medication is not necessary [4]. PPIs also are recommended to prevent nonsteroidal antiinflammatory drug (NSAID)- and aspirin-induced ulcers in high-risk patients [5-7] (Table 1) and for the treatment of gastritis. In intensive care, PPIs are indicated for stress ulcer prophylaxis in patients with a risk of bleeding [8]. The use of PPI for patients with Barrett-Oesophagus is controversial, and its role, if any, in the prevention of carcinoma 
Table 1 Rating of indications for proton pump inhibitors

Indications for proton pump inhibitors

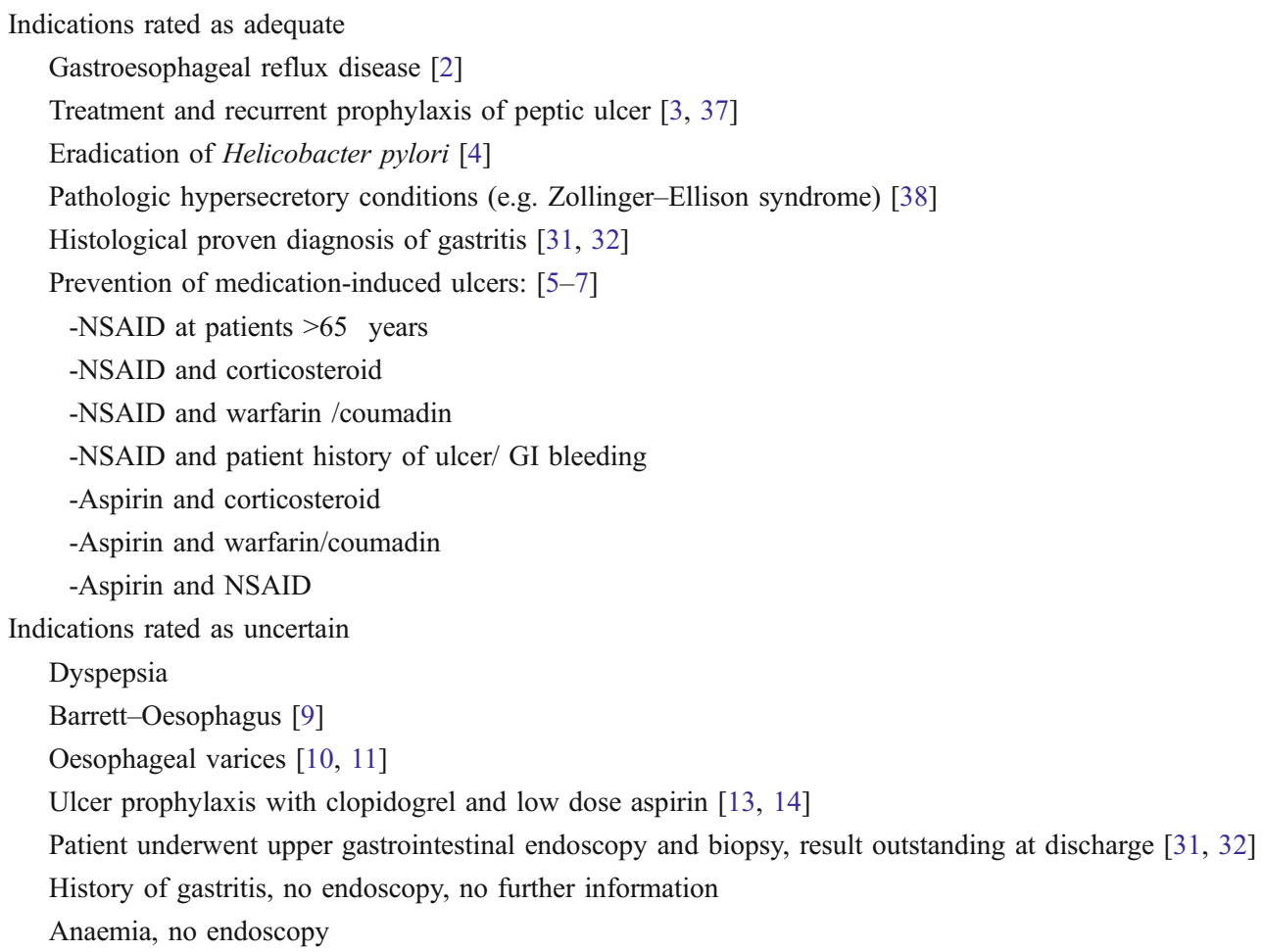

NSAID, Nonsteroidal anti-inflammatory drug

induction has not yet been demonstrated [9]. A Cochrane Review reported that PPIs could be effective in a small proportion of patients with dyspepsia, but studies have shown a significant heterogeneity. Some guidelines recommend testing for $H$. pylori and eradication if necessary, others suggest an empirical PPI treatment $4-8$ weeks as an alternative treatment [10]. Also, there is no clear evidence to support the assumption that PPIs prevent bleeding and promote quicker healing after ligation in patients with liver cirrhosis and oesophageal varices [11]. Some authors recommend ulcer prophylaxis for patients on a combination of aspirin and clopidogrel [12], but there has been some concerns about the interaction of clopidogrel and PPIs reducing cardiovascular protection and increasing arteriosclerotic complications $[13,14]$.

The prescription of PPIs without clear indications has been frequently observed in many countries in hospitals [15-19] and primary care [20] alike. Reported rates of nonindicated prescriptions on general medical wards range from 40 to $81 \%$ [15-19], while inadequate acid-suppressive medication is often continued after discharge for long time $[19,21]$.

Although PPIs are generally considered safe, it has been shown that long-term use might be associated with hip fractures [22, 23], pseudomembranous colitis [24] and respiratory infections, such as pneumonia [25]. In addition, the cost of unnecessary medication burdens the national health budget.

The aim of this study was to analyse the appropriateness of PPI treatment recommendations in patients discharged from hospital in a large German county.

\section{Methods}

This cross-sectional observational study was conducted in 35 primary care practices in the state of MecklenburgVorpommern (MV), North-Eastern Germany.

Recruitment of practices We invited all 933 registered general practitioner (GP) practices in MV to participate in the study. Addresses were obtained from the Association of Statutory Health Insurance Physicians (Kassenaerztliche Vereinigung). A total of 97 GPs agreed to participate the study, respresenting 35 practices (Fig. 1) The sample was stratified by area: two practices from each of 12 rural districts and six major towns in MV were randomly selected.

Identification of patients Patients included in this study were members of the AOK (Allgemeine Ortskrankenkasse) 


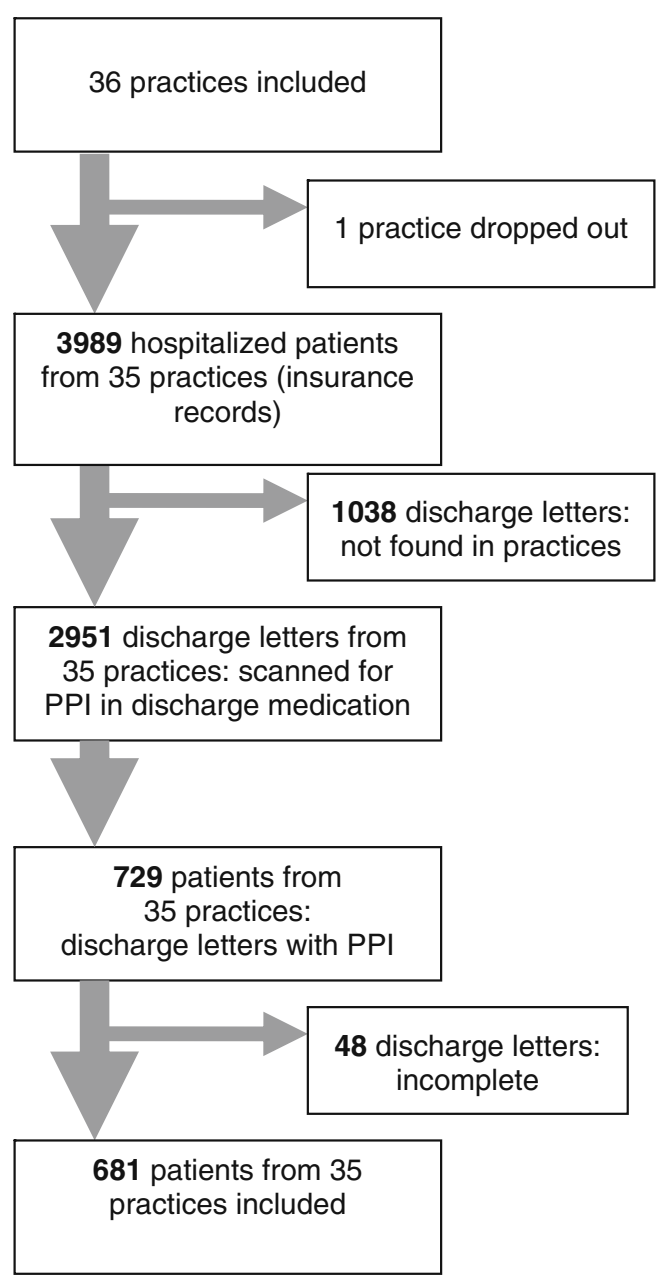

Fig. 1 Patient flow. PPI Proton pump inhibitor

MV, the largest statutory health insurance organization, covering $27 \%$ of the population in MV. All patients from the participating practices $>18$ years of age discharged from hospital between 1 July 2006 and 30 June 2007 were identified from insurance records. In patients with multiple hospital admission, only the first discharge was included. Patients who have received intensive care treatment were excluded.

Data collection Practice nurses received an instruction folder containing the names of all PPI preparations available in Germany. They were asked to screen discharge letters of all the patients identified for PPIs in the discharge medication. Letters recommending PPIs were copied, anonymized and sent to the study centre.

Two raters (DA and GB) assessed all clinical information available in the discharge letter (including comedication) justifying a recommendation for continuous treatment with PPIs. The indication was rated as adequate, inadequate or uncertain (Table 1). Adequate use of a PPI was defined on the basis of approved indications (as written in the official product information) and indications supported by clinical guidelines and scientific literature. If the PPI recommendation was rated as inadequate, we analysed the discharge letter to assess what may have triggered the decision. Differences in judgment between the authors were resolved by discussion.

The study was approved by the Ethics Committee of the medical school of the University of Göttingen.

Statistical analysis Simple descriptive statistics were used. To explore factors associated with inadequate recommendation of PPI, we conducted univariate analyses comparing patients who received an adequate PPI recommendation with those who did not. In a second step, we performed logistic regression analysis to calculate the probability of receiving an inadequate PPI recommendation. We excluded patients with an uncertain indication from the regression model. Covariates retained in the final model were selected with the score procedure. Goodness of fit was assessed with the Hosmer Lemshow test. The software package SAS 9.2 (SAS, Cary, NC) was used for the analysis.

\section{Results}

In the participating practices, a total of 2,951 patients discharged from hospitals were identified in the respective time period. Practice nurses identified 681 (23\%) hospital discharge letters containing a recommendation for PPIs. The patient flow is shown in Fig. 1. Of the participating patients, $382(57 \%)$ were female, and the mean age ( \pm standard deviation) was $70.7( \pm 13.7)$ years. Demographic data on the patient cohort and co-medications used by these patients discharged with PPI are shown in Table 2. H. pylori testing was performed in $96(14.2 \%)$ of 209 patients who had a documented upper gastrointestinal endoscopy, of whom 44 tested positive. Seventeen patients had no pathologic findings on endoscopy and did not take any ulcer-inducing medication.

No information justifying the recommendation for continuous PPI medication could be identified in 371 $(54.5 \%)$ of all discharge letters; in $12.7 \%$, the indication was uncertain, and in $32.7 \%$, we found an evidence-based indication for PPI medication. The most common indication for adequate PPI use was NSAID-prophylaxis in high-risk patients, followed by endoscopically proven gastritis. In patients without an adequate indication, the most common "finding" in the discharge letter was that there was no reason given for the continuous prescription of the PPI; the next most common reason was ulcer prophylaxis in patients taking low-dose aspirin alone (Table 3). 
Table 2 Baseline socio-demographic and clinical characteristics and univariate analysis of the association with inadequate prescription of PPI

\begin{tabular}{|c|c|c|}
\hline Baseline socio-demographic and clinical characteristics $(n=681)$ & Values $^{\mathrm{b}}$ & $\begin{array}{l}\text { Comparison of inadequate with adequate PPI recommendation } \\
(n=594)^{\mathrm{c}}\end{array}$ \\
\hline Age $^{\mathrm{a}}$, years $( \pm \mathrm{SD})$ & $71( \pm 14)$ & n.s. \\
\hline \multicolumn{3}{|l|}{$\operatorname{Sex}^{\mathrm{a}}$} \\
\hline Female & $382(57.0)$ & OR $0.87(0.6-1.2)$ \\
\hline Male & $299(43.0)$ & \\
\hline Length of stay median, days ${ }^{\mathrm{a}}$ (IQR) & $9(6-14)$ & n.s. \\
\hline Hospital category $^{\mathrm{a}}$ & & n.s. \\
\hline Primary/regional care & $214(31.4)$ & \\
\hline Secondary dare centres & $266(39.0)$ & \\
\hline Tertiary care centres & $100(14.7)$ & \\
\hline Specialty care centres & $101(14.8)$ & \\
\hline Endoscopy $^{\mathrm{a}}$ & $209(30.7)$ & OR $0.18(0.12-0.16)$ \\
\hline Testing for $H$. pylori $^{\mathrm{a}}$ & $96(15.0)$ & OR $0.1(0.06-0.18)$ \\
\hline \multicolumn{3}{|l|}{ Co-medication ${ }^{\mathrm{a}}$} \\
\hline None & $16(2.3)$ & OR $0.26(0.09-0.77)$ \\
\hline NSAID & $85(12.5)$ & OR $0.15(0.08-0.25)$ \\
\hline Aspirin (low dose) & $243(36.0)$ & OR $1.2(0.8-1.73)$ \\
\hline Coxib & $23(3.4)$ & OR $1.96(0.71-5.4)$ \\
\hline Corticoid & $59(8.7)$ & OR $0.66(0.38-1.1)$ \\
\hline Warfarin/coumadin & $54(7.9)$ & OR $0.4(0.22-0.69)$ \\
\hline Polypharmacy $^{\mathrm{a}}$ ( $>5$ substances) & $520(76.4)$ & OR $1.15(0.79-1.68)$ \\
\hline
\end{tabular}

NSAID, Non-steroidal anti-inflammatory drug; PPI, proton pump inhibitor; SD, standard deviation; IQR, interquartile range; n.s., not significan

${ }^{\text {a }}$ Significant associations

${ }^{\mathrm{b}}$ Unless stated otherwise, data are given as the number $(n)$ with the percentage in parenthesis

${ }^{\mathrm{c}}$ Patients with indeterminate indication for PPI were excluded. Values are given as the odds ratio (OR) with the $95 \%$ confidence interval in parenthesis

Univariate analysis revealed that factors associated with a lower risk of inadequate recommendation for PPIs were endoscopy [odds ratio (OR) $0.18,95 \%$ confidence interval (CI) 0.12-0.16], testing for H. pylori (OR $0.1,95 \%$ CI $0.06-$ 0.18 ), NSAID (OR $0.15,95 \%$ CI $0.08-0.25$ ) or oral anticoagulation (OR $0.4,95 \%$ CI $0.22-0.69$ ). No association was found with age, gender, polypharmacy (defined as $>5$ concomitant medications) and hospital type (Table 2). After adjustment with multivariate analysis, endoscopy (OR 0.13 , 95\% CI 0.08-0.22), testing for H. pylori (OR $0.1,95 \%$ CI $0.06-0.18$ ), co-medication of NSAIDs (OR $0.14,95 \% \mathrm{CI}$ $0.09-0.21$ ) or oral anticoagulation (OR $0.24,95 \%$ CI 0.12 $0.49)$ remained significant factors that decreased the risk of inadequate PPI recommendation $\left(R^{2} 0.48\right)$.

The most commonly prescribed PPI was pantoprazole ( $n=$ 487, 72\%). Recommended daily doses are shown in Table 4.

\section{Discussion}

Our study confirms that PPIs in hospitals are often prescribed without a clear indication. In $54.5 \%$ of the discharge letters recommending PPIs analysed, no appro- priate indication justifying continuous prescription could be identified, and in $12.8 \%$, the indication was uncertain.

Current guidelines recommend peptic ulcer prophylaxis only for intermediate- to high-risk patients; in the absence of risk factors, no peptic ulcer prevention is necessary in patients using NSAID or low-dose acetylsalicylic acid (ASA) $[5,7]$. In addition, there is evidence that concomitant use of PPIs might reduce the cardiovascular protection provided by aspirin [26]. Concerns also exist about the interaction of PPI and clopidogrel with respect to possible increases in arteriosclerotic complications [13, 14]. We therefore rated ulcer prophylaxis in the combination of aspirin and clopidogrel as an uncertain indication, but it should be taken into account that the studies reporting these associations were published after our study sampling period. Steroids without concomitant NSAID therapy do not significantly increase the risk of peptic ulcers [27]. No ulcer prophylaxis is necessary for oral anticoagulation drugs administered in the therapeutic range to patients without a history of ulcer/bleeding or concomitant NSAID treatment [28].

Stress ulcer prophylaxis is recommended only for high risk-patients in intensive care units (ICU) wards. For these 
Table 3 Rating of indication, results and categories $(n=681)$

\begin{tabular}{|c|c|c|}
\hline Rating of indication for PPI & Presumed reason for recommendation of continuous prescription of PPIs & Number $(\%)$ \\
\hline \multirow[t]{5}{*}{ Adequate documented indication $(n=223 ; 32.8 \%)$} & NSAID in high-risk patients & $90(40.4)$ \\
\hline & Gastric or duodenal ulcer & $46(20.6)$ \\
\hline & GERD & $45(20.2)$ \\
\hline & Proven gastritis with/ without helicobacter & $37(16.6)$ \\
\hline & $\begin{array}{l}\text { Macroscopic erosion or erythema, no biopsy because of oral } \\
\text { anticoagulation }\end{array}$ & $5(2.2)$ \\
\hline \multirow[t]{7}{*}{ Documented indication uncertain $(n=87 ; 12.8 \%)$} & Clopidogrel and low dose aspirin & $43(49.4)$ \\
\hline & Macroscopic gastric erythema or erosion, result outstanding at discharge & $13(15.0)$ \\
\hline & History of gastritis, no endoscopy, no further information & $10(11.5)$ \\
\hline & Oesophageal varices & $10(11.5)$ \\
\hline & Barrett-Oesophagus & $5(5.7)$ \\
\hline & Dyspepsia & $4(4.6)$ \\
\hline & Anaemia, no endoscopy & $2(2.3)$ \\
\hline \multirow{10}{*}{$\begin{array}{l}\text { No documented adequate indication } \\
(n=371 ; 54.4 \%)\end{array}$} & No reason for PPI found & $140(37.8)$ \\
\hline & Low-dose aspirin, no documented history of bleeding & $108(29.1)$ \\
\hline & Macroscopic gastric erythema or erosion, no biopsy, no $H$. pylori testing & $27(7.3)$ \\
\hline & NSAID $<65$ y, no history of bleeding & $23(6.2)$ \\
\hline & Clopidogrel alone & $23(6.2)$ \\
\hline & Corticosteroid alone & $21(5.7)$ \\
\hline & Oral anticoagulation & $15(4.0)$ \\
\hline & Coxib alone & $9(2.4)$ \\
\hline & PPI after completed $H$. pylori-treatment, eradication, no ulcer & $3(0.8)$ \\
\hline & Corticosteroid and oral anticoagulation & $2(0.5)$ \\
\hline
\end{tabular}

GERD. Gastroesophageal reflux disease

patients, respiratory failure requiring mechanical ventilation and coagulopathy have been identified as strong independent risk factors [29]. The American Society of Health Service guidelines also denote sepsis and specific illnesses, such as spinal cord injury, as determining factors for stress ulcer prophylaxis [30]. Patients from ICU wards were excluded from our study.

The diagnosis of gastritis is based on histological examination of the gastric mucosa. Macroscopic signs, such as erythema or erosion, are of very limited value in the evaluation of gastritis and H. pylori infection [31, 32]. We consider the recommendation of continuous PPI therapy based only on visual findings of macroscopic erythema or erosion to be inadequate if there were no contraindications for biopsy and no biopsy was taken.

We assume that low-dose aspirin or NSAIDs in low-risk patients, steroid therapy or oral anticoagulant treatment may have been a frequent trigger for inappropriate prescriptions (Table 3). For more than one third of inappropriate PPI prescriptions, we found no explanation.

Doctors may not be aware of existing guidelines and use PPIs uncritically in good faith as stress ulcer prophylaxis without indication. Inappropriate assumptions about the risk of ulcer development during hospitalization may also be an explanation for the prescribing behaviour. Although endoscopy, testing for $H$. pylori and co-medication with

Table 4 Recommended PPI/ daily doses

\begin{tabular}{lllll}
\hline $\begin{array}{l}\text { PPI type: } \\
n=\end{array}$ & $\begin{array}{l}\text { Pantoprazole } \\
487(71.5 \%)\end{array}$ & $\begin{array}{l}\text { Esomeprazole } \\
116(17.0 \%)\end{array}$ & $\begin{array}{l}\text { Omeprazole } \\
77(11.3 \%)\end{array}$ & $\begin{array}{l}\text { Lansoprazole } \\
1(0.2 \%)\end{array}$ \\
\hline $\begin{array}{l}\text { No dosage } \\
20 \mathrm{mg}\end{array}$ & $4(0.8 \%)$ & $1(0.9 \%)$ & $3(3.9 \%)$ & \\
$40 \mathrm{mg}$ & $104(21.3 \%)$ & $60(51.7 \%)$ & $49(63.6 \%)$ & \\
$80 \mathrm{mg}$ & $312(64.1 \%)$ & $47(40.5 \%)$ & $20(26 \%)$ & $1(100 \%)$ \\
$120 \mathrm{mg}$ & $65(13.4 \%)$ & $8(6.9 \%)$ & $5(6.5 \%)$ & \\
\hline
\end{tabular}


NSAIDs or oral anticoagulation were factors that significantly decreased the risk of inadequate PPI prescribing, more than half of these patients had no identifiable indication for PPI prescription. It is notable that 17 patients in our sample underwent endoscopy and were subsequently prescribed PPIs, although no pathology was found and no ulcerogenic medication was administered.

The high rates of inappropriate PPI prescriptions in hospitals observed in our study are consistent with rates published from other studies. Two Swedish studies found that $59-81 \%$ of hospitalized patients received acid suppression therapy without appropriate indication $[16,18]$, while two Italian studies reported $41.5 \%$ [17] and $68 \%$, respectively. [21] A 1-day survey at an Irish hospital revealed that $30 \%$ of patients were on PPI medication; of these, $71 \%$ were started on PPIs in hospital and 33\% had no evidence-based indication [15]. An American study found that $60 \%$ of PPI treatments started in the hospital had no medical basis [19]; after discharge $46-80 \%$ and $50 \%$ of these patients were still on PPIs after 3 and 6 months, respectively [19, 21].

Inappropriate prescribing of PPIs is an important issue mainly for two reasons. First, the administration of unnecessary medication leads to polypharmacy and can lead to side-effects and pharmacological interactions. PPI use has been found to have a significant association with community-acquired pneumonia [25] and Clostridium difficile-associated diarrhoea [24] Long-term PPI therapy has been suspected to be associated with an increased risk of hip fractures $[22,23]$.

PPIs are a major burden for the national healthcare budget. It was very noticeable that more than two thirds of the discharge letters analysed recommended pantoprazole which, at the time of the study, was much more expensive than the generic omeprazole. At equipotent doses, different PPIs are considered to be equally efficient in inhibiting gastric acid secretion [33, 34]. Hospitals significantly influence drug prescription behaviour in the primary care setting [35]. Moreover, in Germany, many hospitals receive PPIs at no or minimal cost, and manufacturers expect that continued prescribing in primary care will reimburse them for this initial "loss" [36]

This is the first study in Germany to assess the appropriateness of PPI prescribing in hospital discharge letters. Theoretically, it is possible that the GP practices participating in our study failed to identify all discharge letters with a PPI recommendation. However, it is unlikely that such an omission would have introduced a significant selection bias. Our assessment of the appropriateness of the drug recommendation is solely based on information available in the discharge letter; consequently, the numbers of inappropriate PPI recommendations may be slightly overestimated. Nevertheless, discharge letters should provide sufficient information to allow the GP to understand the recommendation when specific hospital drugs are to be continued in the primary care setting.

Hospitals should critically review their practice of recommending PPIs in their discharge letters and clearly document the reason for continued PPI use after discharge. Likewise, GPs should carefully assess the need for continuous prescription. The reasons why evidence-based clinical guidelines are obviously not observed merits further research.

Acknowledgements This study was financed by the German Ministry for Education and Science (BMBF); grant number 01GK0711. No other financial support was received. We are indebted to the AOK Statutory Health Insurance Mecklenburg-Vorpommern who helped to identify discharged patients.

\section{Conflict of interests None}

Open Access This article is distributed under the terms of the Creative Commons Attribution Noncommercial License which permits any noncommercial use, distribution, and reproduction in any medium, provided the original author(s) and source are credited.

\section{References}

1. Mössner J (2009) Magen Darm Mittel und Laxantien. In: Schwabe U, Paffrath D (eds) Drug prescription report 2009 [Arzneiverordnungsreport 2009]. Springer, Heidelberg, pp 653-681

2. Moayyedi P, Talley NJ (2006) Gastro-oesophageal reflux disease. Lancet 367:2086-2100

3. Leontiadis GI, Sharma VK, Howden CW (2006) Proton pump inhibitor treatment for acute peptic ulcer bleeding. Cochrane Database Syst Rev CD002094

4. Malfertheiner P, Megraud F, O'Morain C, Bazzoli F, El Omar E, Graham D et al (2007) Current concepts in the management of Helicobacter pylori infection: the Mastricht III Consensus Report. Gut 56:772-781

5. Dubois RW, Melmed GY, Henning JM, Laine L (2004) Guidelines for the appropriate use of non-steroidal anti-inflammatory drugs, cyclo-oxygenase-2-specific inhibitors and proton pump inhibitors in patients requiring chronic anti-inflammatory therapy. Aliment Pharmacol Ther 19:197-208

6. Chan FK, Graham DY (2004) Review article: prevention of nonsteroidal anti-inflammatory drug gastrointestinal complicationsreview and recommendations based on risk assessment. Aliment Pharmacol Ther 19:1051-1061

7. Lanza FL, Chan FK, Quigley EM (2009) Guidelines for prevention of NSAID-related ulcer complications. Am J Gastroenterol 104:728-738

8. Quenot JP, Thiery N, Barbar S (2009) When should stress ulcer prophylaxis be used in the ICU? Curr Opin Crit Care 15:139-143

9. Armstrong D, Marshall JK, Chiba N, Enns R, Fallone CA, Fass R et al (2005) Canadian Consensus Conference on the management of gastroesophageal reflux disease in adults - update 2004. Can J Gastroenterol 19:15-35

10. Talley NJ, Vakil N (2005) Guidelines for the management of dyspepsia. Am J Gastroenterol 100:2324-2337

11. Lodato F, Azzaroli F, Di Girolamo M, Feletti V, Cecinato P, Lisotti A et al (2008) Proton pump inhibitors in cirrhosis: tradition or evidence based practice? World J Gastroenterol 14:2980-2985 
12. Ng FH, Lam KF, Wong SY, Chang CM, Lau YK, Yuen WC et al (2008) (2009) Upper gastrointestinal bleeding in patients with aspirin and clopidogrel co-therapy. Digestion 77:173-177

13. O'Donoghue ML, Braunwald E, Antman EM, Murphy SA, Bates ER, Rozenman Y, et al. Pharmacodynamic effect and clinical efficacy of clopidogrel and prasugrel with or without a protonpump inhibitor: an analysis of two randomised trials. Lancet 374:989-997

14. Ho PM, Maddox TM, Wang L, Fihn SD, Jesse RL, Peterson ED et al (2009) Risk of adverse outcomes associated with concomitant use of clopidogrel and proton pump inhibitors following acute coronary syndrome. JAMA 301:937-944

15. Mat Saad AZ, Collins N, Lobo MM, O'Connor HJ (2005) Proton pump inhibitors: a survey of prescribing in an Irish general hospital. Int J Clin Pract 59:31-34

16. Niklasson A, Bajor A, Bergendal L, Simren M, Strid H, Bjornsson E (2003) Overuse of acid suppressive therapy in hospitalised patients with pulmonary diseases. Respir Med 97:1143-1150

17. Scagliarini R, Magnani E, Pratico A, Bocchini R, Sambo P, Pazzi $P$ (2005) Inadequate use of acid-suppressive therapy in hospitalized patients and its implications for general practice. Dig Dis Sci 50:2307-2311

18. Strid H, Simren M, Bjornsson ES (2003) Overuse of acid suppressant drugs in patients with chronic renal failure. Nephrol Dial Transplant 18:570-575

19. Zink DA, Pohlman M, Barnes M, Cannon ME (2005) Long-term use of acid suppression started inappropriately during hospitalization. Aliment Pharmacol Ther 21:1203-1209

20. Hungin AP, Rubin GP, O'Flanagan H (1999) Long-term prescribing of proton pump inhibitors in general practice. Br J Gen Pract 49:451-453

21. Parente F, Cucino C, Gallus S, Bargiggia S, Greco S, Pastore L et al (2003) Hospital use of acid-suppressive medications and its fallout on prescribing in general practice: a 1-month survey. Aliment Pharmacol Ther 17:1503-1506

22. Vestergaard P, Rejnmark L, Mosekilde L (2006) Proton pump inhibitors, histamine $\mathrm{H} 2$ receptor antagonists, and other antacid medications and the risk of fracture. Calcif Tissue Int 79:76-83

23. Yang YX, Lewis JD, Epstein S, Metz DC (2006) Long-term proton pump inhibitor therapy and risk of hip fracture. JAMA 296:2947-2953

24. Dial S, Delaney JA, Barkun AN, Suissa S (2005) Use of gastric acid-suppressive agents and the risk of community-acquired Clostridium difficile-associated disease. JAMA 294:2989-2995

25. Laheij RJ, Sturkenboom MC, Hassing RJ, Dieleman J, Stricker BH, Jansen JB (2004) Risk of community-acquired pneumonia and use of gastric acid-suppressive drugs. JAMA 292:1955-1960
26. Wurtz M, Grove EL, Kristensen SD, Hvas AM (2010) The antiplatelet effect of aspirin is reduced by proton pump inhibitors in patients with coronary artery disease. Heart 96:368-371

27. Piper JM, Ray WA, Daugherty JR, Griffin MR (1991) Corticosteroid use and peptic ulcer disease: role of nonsteroidal antiinflammatory drugs. Ann Intern Med 114:735-740

28. Petty GW, Brown RD Jr, Whisnant JP, Sicks JD, O'Fallon WM, Wiebers DO (1999) Frequency of major complications of aspirin, warfarin, and intravenous heparin for secondary stroke prevention. A population-based study. Ann Intern Med 130:14 22

29. Cook DJ, Fuller HD, Guyatt GH, Marshall JC, Leasa D, Hall R et al (1994) Risk factors for gastrointestinal bleeding in critically ill patients. Canadian Critical Care Trials Group. N Engl J Med 330:377-381

30. ASHP Therapeutic Guidelines on Stress Ulcer Prophylaxis (1999) ASHP Commission on Therapeutics and approved by the ASHP Board of Directors on November 14, 1998. Am J Health Syst Pharm 56:347-379

31. Redeen S, Petersson F, Jonsson KA, Borch K (2003) Relationship of gastroscopic features to histological findings in gastritis and Helicobacter pylori infection in a general population sample. Endoscopy 35:946-950

32. Sauerbruch T, Schreiber MA, Schussler P, Permanetter W (1984) Endoscopy in the diagnosis of gastritis. Diagnostic value of endoscopic criteria in relation to histological diagnosis. Endoscopy $16: 101-104$

33. Sachs G, Shin JM, Howden CW (2006) Review article: the clinical pharmacology of proton pump inhibitors. Aliment Pharmacol Ther 23[Suppl 2]:2-8

34. Hellstrom PM, Vitols S (2004) The choice of proton pump inhibitor: does it matter? Basic Clin Pharmacol Toxicol 94:106111

35. Grimmsmann T, Schwabe U, Himmel W (2007) The influence of hospitalisation on drug prescription in primary care - a large-scale follow-up study. Eur J Clin Pharmacol 63:783-790

36. Kochen MM, Niebling W (2006) Proton pump inhibitorsinformation on rational pharmacotherapy in primary care [Protonenpumpenhemmer-Informationen zur rationalen Arzneitherapie in der hausärztlichen Praxis]. Arzneitelegramm 37:104-06

37. Freston JW (2001) Review article: role of proton pump inhibitors in non-H. pylori-related ulcers. Aliment Pharmacol Ther 15[Suppl 2]:2-5

38. Wilcox CM, Hirschowitz BI (2009) Treatment strategies for Zollinger-Ellison syndrome. Expert Opin Pharmacother 10:11451157 